https://doi.org/10.48009/2_iis_2008_211-218

\title{
AMPLIFYING TEAMWORK ISSUES THROUGH THE USE OF SITUATIONAL VIGNETTES
}

\author{
James J. Cappel, Central Michigan University, james.cappel@cmich.edu
}

\begin{abstract}
Information systems (IS) work takes place predominantly in a team-based environment. To simulate the work environment and develop teamwork skills in students IS courses often use teambased projects. A common dilemma faced by IS instructors is how much emphasis to give teamwork in the classroom while working under tight time constraints to cover the other course content. This paper reports the results of an approach designed to promote better teamwork in an information systems course. Vignettes about teamwork issues were used early in a course to raise potential, salient team problems. The results of this study based on more than 130 participants suggests that this approach appears to be an efficient and effective way to address teamwork issues and set expectations for team member performance. This article presents guidelines for implementing this approach successfully.
\end{abstract}

Keywords: Information systems instruction; information systems job skills; project management; systems development

\section{INTRODUCTION}

Employers often stress to information systems educators the importance of students developing "soft skills," or non-technical skills, along with technical skills in their IS programs. Given the team-based environment and people-intensive nature of many IS positions, it is not surprising that various studies have found that IS employers rate many non-technical skills even more important than technical skills [7, 32, 34, 35, 38]. Litecky et al. [24] propose that IS employers may follow a two-stage model in hiring, using technical skills as a screening device and then emphasizing soft skills in the actual hiring decision. Among the top soft skills sought by employers is teamwork [7, 32, 34], the ability to work effectively with others to accomplish a common goal. Additionally, the IS 2002 Model Curriculum and Guidelines for Undergraduate Degree Programs in Information Systems identifies "interpersonal, communication, and team skills" as one of the four main skill areas for IS graduates [17].
To develop team skills, many IS courses make extensive use of project teams where students work together over weeks or months to complete project milestones or develop systems or prototypes. These experiences allow students to perform activities that mirror the responsibilities of IS professionals in the workplace. However, almost every IS instructor has encountered situations where teams have either underperformed or failed on projects. These situations often result from team management issues or "people problems" such as miscommunication, inflexibility, lack of planning, procrastination, or excessive conflict between team members. These problems can be very distracting as a team must devote attention to issues such as how to handle a "problem" group member instead of addressing the project at hand. This can lead to teams underperforming on a project and to members harboring feelings of dissatisfaction toward the course, the instructor, or other students.

Conscientious instructors want to do everything in their power to avoid these situations and create positive conditions for team success. Instructors can potentially affect team performance through team composition, orientation, task assignment, mentoring, feedback, and evaluation processes. The extent to which an instructor gets involved in these activities is, in part, a function of personal style and what assumptions he/she makes about students' prior background. For example, some instructors may contend that they do not need to teach students anything about working in teams since they should already know this. Others may elect for a more active approach. One thing is more certain: the amount of time that IS instructors have to devote to team management issues is extremely limited given the demands to address other course topics.

The approach to improving team processes proposed in this paper is most closely associated with the team management process of orientation, i.e., trying to establish clear expectations about team members' roles and responsibilities prior to embarking on a project. This approach uses the power of stories to raise awareness about potential team problems, so as to avoid problems from arising and raise some possible solutions to them should they arise. Vignettes have been applied in a variety of other 
business, research, and educational settings. However, no previous studies were identified from a literature review that evaluated the use of vignettes for enhancing teamwork. That is the focus of this investigation.

\section{LITERATURE REVIEW}

A vignette, which may also be called a scenario, is essentially a short case or story. It is usually presented in several sentences over a limited number of paragraphs, and it describes a situation that requires decision making or problem solving. In contrast, a case can range from a few sentences to more than forty pages [30].

The use of stories to communicate messages, raise moral issues, and teach lessons has been around literally for thousands of years. In early times, myths, legends, and folk tales were passed down by societies through oral tradition [31]. The Christian Bible consists largely of stories designed to teach moral lessons. Over the past few years, the use of storytelling for leading organizations has also achieved prominence. For example, books by Denning have emphasized the importance of stories for change management and knowledge management purposes [6, 13, 14]. A Director at the Boeing Company who reviewed one of Denning's books comments, "Storytelling is the single most effective way to communicate a change in an organization. Through stories, people visualize events, understand concepts and engage their hearts and minds. Vision and mission statements people read, walk out of a room, and two days later cannot remember. But tell them a story and they will not only remember it, they will repeat it” [6].

Vignettes have also been used as a tool to help decision makers envision and plan for different alternative versions of the future. They have been used extensively by top managers for strategic planning purposes and by emergency planning personnel in preparing for natural disasters, security breaches, and terrorism attacks [29]. Vignettes have also been applied for research purposes such as to study ethical decision making behavior [e.g., 9, 12, 26], and use of cases for educational purposes is well established in various fields such as medicine, nursing, law, engineering, and business [30].

In education, vignettes can provide a number of important advantages including: (1) they engage participants in active problem solving; (2) "they help make up for students lack of real world experience" [30, p. 169]; (3) they help students gain experience with problems that may have more than one valid solution [30]; (4) they can serve as excellent homework assignments and springboards for discussion [30]; and (5) in terms of Bloom's typology, they can be used to foster higher-level critical thinking such as application, analysis, synthesis, and evaluation [3]. Vignettes can require participants to apply theories or concepts to situations, look at problems from multiple vantage points, distinguish relevant from irrelevant facts, brainstorm possible solutions, evaluate alternatives, and recommend and justify the "best" course of action. Moreover, when vignettes are discussed or solved in a team, they can promote interpersonal and oral communication skills, problem solving, and teamwork - skills that research shows IS employers highly value [7, 18, 19, 32, 33].

As noted earlier, many types of problems can occur in a team setting that hinder task performance and member relations. Among these are: "free riding," or not contributing a fair share toward the overall team effort, holding unyielding opinions, not being sufficiently available and flexible for team meetings, and procrastination [16, 21, 25, 27, 37]. Since vignettes are problem-based, they provide "fertile ground" for raising team problems and provoking discussion of a range of team management issues in a succinct way.

To create conditions for team success, various writers have offered recommendations for team composition, orientation, task and role assignment, feedback and evaluation practices. For example, some sources advise assigning students to heterogeneous groups that balance background, experience, and diversity factors rather than allowing students to self-select their own team members [e.g., 2, 11, 36]. Other writers recommend assigning roles to different members to reduce problems such as "free riding," ambiguity, and conflict [27, 37], and others point out the importance of completing peer evaluations for projects [5, 10, 15, 23, 25].

This study proposes using vignettes to address teamwork issues, an issue that has received little attention in prior research. One research question considered is: what are students' perceptions about use of this approach in an information systems course? Second, since learner characteristics such as age and experience can impact the way students respond to certain instructional strategies [20,30], the second research question examined is: are there any significant differences in students' perceptions of the vignette approach between undergraduate and graduate students? 


\section{METHODOLOGY}

This study was undertaken in two IS courses at a large public university in the Midwest: an undergraduate Systems Analysis and Design course and a graduate Information Resources Management course. Both courses made extensive use of student project-based teams over most of the semester. An instrument composed of several vignettes about team-based problems was developed by the author based on team problems identified in the literature and the author's more than ten years experience using teams in various IS courses. The vignettes raise a range of team-based issues or problems. Five sample scenarios in the instrument are presented in the Appendix. For each vignette, subjects were asked to complete open-ended questions that addressed identifying the problem of the story, its impacts, some possible causes, and which actors should have acted differently. To enhance realism, minor wording changes were made to the vignettes based on which course it was used. In the Systems Analysis and Design course, the vignettes were described as occurring in a "systems analysis and design course" (as shown in the Appendix) whereas in the graduate course, this expression was changed to an "information systems course." Otherwise, the vignettes contained identical wording and the same data collection procedures were used in both courses. In the first week of the semester, students were given an assignment to complete the team vignettes instrument, which was made available to student electronically through the course management system, Blackboard.

In the subsequent class, the instructor and students engaged in class discussion of the vignettes and teamwork-related issues for approximately thirty to forty minutes. The vignettes were also used as a springboard for discussion of related teamwork issues such as the team member evaluation policy that would be used in this course and the use of electronic team capabilities available to teams in Blackboard.

Following class discussion, students completed an anonymous survey to solicit their opinions about this experience. The overall sample consisted of about two-thirds males (67\%) and one-third females (33\%). Among undergraduates, most were seniors (78\%) while the remainder was juniors (22\%). More than two-thirds of the overall sample (67\%) was MIS majors, while the remaining students consisted mostly of Computer Science (17\%) and Accounting (12\%) majors. Over three-fourths of the entire sample (77\%) reported that they had taken three or more courses where team projects were used over several weeks. Statistical tests of significance revealed that the undergraduate and graduate samples did not differ significantly by gender or previous experience using teams. A total of 90 of 92 undergraduates enrolled in the undergraduate course and all 41 students enrolled in the graduate course participated in the study, comprising a total of 131 subjects. This represents a participation rate of $98 \%$ for undergraduates and $100 \%$ for graduates.

\section{RESULTS AND DISCUSSION}

Since one important factor affecting the success of the use of vignettes is realism [8, 29, 31], two survey items were included to assess the perceived realism of the scenarios among respondents. In the overall sample, $86 \%$ reported that they had experienced some of the team problems described in the vignettes, while only $12 \%$ said they had not. Additionally, more than two-thirds of the total sample (68\%) indicated they thought that some of the problems described in the vignettes were "very likely" to happen in a class-related team project, while $27 \%$ said they were "somewhat likely" to occur, and only $3 \%$ said they were not likely to occur. These results suggest that most students viewed the problems raised in the vignettes as credible or realistic. The data showed no statistically significant differences on these measures across the graduate and undergraduate samples.

The results for various other measures of respondents' perceptions of the vignettes using a seven-point agree-disagree scale are presented in Table 1. As indicated in the table, the mean response among all participants for seven of the eight measures is 5.2 or higher where " 7 " is the most positive response. The two items for which respondents showed the highest level of agreement were: "if some of the problems described in the vignettes actually happened, they could have an important effect on whether a group achieved success on a project" (6.27); and that the exercise provided "practice solving group problems we might face" (6.01). Respondents also indicated a rather high level of agreement that the exercise should be used in the course in the future (5.87) and that it was "useful" (5.77). Overall, these findings suggest that many students saw some important benefits to using the vignettes approach.

Specific benefits of using this approach mentioned by respondents in open-ended survey responses included that this exercise: "was preparation for the group project;" "gave light to many different possible group problems;" "gave us a chance to think about what we 
should do if we run into these problems this semester;" "got people thinking about these issues so they would not do any of them;" and "helped me learn the expectations of the instructor." Another student commented, "By discussing it in class, I learned more ways to deal with problems." Another observed, "Since we talked about it as a class, I think the students have a better idea about acceptable group behavior and will therefore work with each other better than if we hadn't done the exercise."

Two measures in Table 1 for which there was less consensus, as indicated by their higher standard deviations and lower means, involved whether this exercise raised "something new." Specifically, the mean for the item, "by discussing the vignettes in class, I heard some ideas expressed by others that I did not think about previously" was 5.20 and the mean for the item that the exercise "raised problems about working in groups that I never thought about before" was 4.51. While both of these means are on the positive side of the seven-point scale, they were the lowest among the eight response items in the table. These results appear to be consistent with the finding noted earlier that most participants (86\%) indicated that they had previously experienced some of the problems described in the vignettes. What the findings may suggest is that while the vignettes do not raise many entirely "new" issues - i.e., problems that students have not thought about before - they can serve as reminders of what to do and not do in a team. In addition, even if a student learns only one good "take away" from a discussion sometimes it can make an important difference.

The second research question involves whether there were any differences between graduates and undergraduates with respect to their perceptions of the vignette-based approach. As indicated in Table 1, five of eight outcome measures were rated significantly higher by graduate students than undergraduates, suggesting that the vignette approach was received somewhat more favorably by graduate students. This outcome is consistent with the observations and research of educational authorities such as Bash, Knowles, and Nilson [1, 22, 30] that "non-traditional" (or adult) learners, i.e., those 25 years of age and older: tend to be more self-directed; desire greater control over their learning; have greater life experience and want to share it with others; are practical and relevancy oriented; and are more problem-centered than subject-centered in learning. The mean age of undergraduates in this study was 22.8 versus 25.3 for graduates, which makes these sample groups fall within the "traditional" and "nontraditional" student categories, respectively. Since the vignette method is problem-based, it provides participants the opportunity to reflect upon and use their life experience, and that would appear to be more appealing to graduates than undergraduates.

Still, in drawing conclusions about use of the case method in general, Bonwell and Eison [4, p. 39] observe, "Although this method has traditionally been used in graduate-level instruction, it can also be effective at the undergraduate level if cases are presented carefully within students' experiential framework." To accomplish this, instructors who use the vignettes approach with undergraduates may want to spend a bit more effort "selling this approach" to students at the time of the initial assignment to provoke students' interest.

\section{IMPLICATIONS AND RECOMMENDATIONS}

As noted earlier, employers expect good teamwork skills in new employees, and IS educators strive to develop these skills in students prior to graduation. The approach presented in this paper, using situational vignettes to highlight important teamwork issues, appears to offer important promise to improve team performance in information systems courses based on several key points: (1) teams are used extensively in IS courses; (2) teams do not always perform up to their capabilities; (3) where this occurs, it can distract from task performance and lead to other undesired outcomes; (4) IS instructors have a responsibility to create conditions to promote positive team performance; (5) the time that IS instructors have to address teamwork issues is limited; (6) vignettes can be powerful tools for learning and remembering significant points; and (7) the results of this study suggest that the vignette approach can be an effective team orientation tool that uses only a limited amount of class time.

This study found that many participants thought that the vignettes raised important issues, were realistic, and useful. Some respondents also expressed in open-ended comments that through this approach, they gained a better understanding of team performance expectations. While graduate students rated this approach more positively than undergraduates on several measures, positive results were also achieved on most outcomes with undergraduates. Thus, initial data suggests the vignette approach offers promise as an educational tool. Since this is an exploratory study, however, there is need for further investigation of this issue. This study focused on students' perceptions. Followup research might address team performance-based outcomes. Another avenue for study is to evaluate 
the use of vignettes in lower level undergraduate courses as opposed to the courses considered here.

To implement the vignettes approach successfully, several recommendation are offered. First, since this is a team orientation exercise, it has the most value if it is done early in a course to prevent team problems and avoid distracting teams from other assigned tasks. Second, if an instructor decides to write custom vignettes rather than using those presented here, it is important to follow guidelines for writing "good cases." Ideally, vignettes should provoke interest, be realistic, be objectively written, have a degree of ambiguity to allow for multiple solutions and valid debate, and be pre-tested prior to use [8, 28]. Third, to ensure that class discussion of the vignettes is engaging, it is important to challenge students with good questions, including raising issues beyond those already raised in the case. For example, students can be queried about questions such as: if a certain fact were changed in a story, would it change your opinion? What information is missing in a case that we would ideally like to know? Finally, feedback should also be solicited from participants and used to refine the approach over time in the interests of continuous improvement.

\section{REFERENCES}

1. Bash, L. (2003). Adult Learners in the Academy. Bolton, MA: Anker Publishing Co.

2. Birmingham, C. \& McCord, M. (2002). "Group Process Research: Implications for Using Learning Groups.” In Team-Based Learning: A Transformative Use of Small Groups in College Teaching. Michaelsen, L., Knight, A., \& Fink, L. eds. Sterling, VA:Stylus Publishing.

3. Bloom, B. (1956). "Cognitive Domain," Taxonomy of Educational Objectives. Handbook 1. New York, NY: David McKay.

4. Bonwell, C. C. \& Eison, J. A. (1991). Active Learning: Creating Excitement in the Classroom. ASHE- ERIC Higher Education Report No. 1. Washington, D.C: The George Washington University, School of Education and Human Development.

5. Brooks C. \& Ammons, J. (2003). "Free Riding in Group Projects and the Effects of Timing, Frequency, and Specificity of Criteria in Peer Assessments," Journal of Education for Business, 78(5), 268-271.

6. Brown, J., Denning, S., Groh, K. \& Prusak, L. (2005). Storytelling in Organizations: Why Storytelling is Transforming $21^{\text {st }}$ Century Organizations and Management. Burlington, MA: Butterworth-Heinemann.
7. Cappel, J. (2001-2002). "Entry-Level IS Job Skills: A Survey of Employers," Journal of Computer Information Systems, 42(2), 76-82.

8. Cappel, J. \& Schwager, P. (2002). "Writing IS Teaching Cases: Guidelines for JISE Submission," Journal of Information Systems Education, 13(4), 287-294.

9. Cappel, J. \& Windsor, J. (2000). "Ethical Decision Making: A Comparison of Computer-Supported and Face-to-Face Groups,” Journal of Business Ethics, 28(2), 95107.

10. Chen Y. \& Lou, H. (2004). "Students' Perceptions of Peer Evaluation: An Expectancy Perspective," Journal of Education for Business, 79(5), 275-282.

11. Colbeck, C., Campbell, S. \& Bjorklund, S. (2000). "Grouping in the Dark," Journal of Higher Education, 71(1), 60-83.

12. Conroy, S. \& Emerson, T. (2004). "Business Ethics and Religion: Religiosity as a

Predictor of Ethical Awareness among Students,” Journal of Business Ethics, 50(4), 383-396.

13. Denning, S. (2004). Squirrel, Inc.: A Fable of Leadership through Storytelling. San Francisco, CA: Jossey-Bass,.

14. Denning, S. (2001). The Springboard: How Storytelling Ignites Action in Knowledge-Era Organizations. Woburn, MA: ButterworthHeinemann.

15. Dyrud, M. (2001). "Group Projects and Peer Review," Business Communication Quarterly, 64(4), 106-112.

16. Fox, T. (2002). "A Case Analysis of Real-World Systems Development Experiences of CIS Students," Journal of Information Systems Education, 13(4), 343-350.

17. Gorgone, J., Davis, G., Valacich, J., Topi, H., Feinstein, D. \& Longnecker, H. (2002). IS 2002 Model Curriculum and Guidelines for Undergraduate Degree Programs in Information Systems. Available at www.acm.org/education/is2002.pdf, Accessed July 17, 2006.

18. Hingorani, K. \& Sankar, C. (1995). "Entry Level MIS Jobs: Industry Expectations Versus Academic Preparation," Journal of Computer Information Systems, 36(4), 18-27.

19. Jiang, J, Udeh, I., \& Hayajneh, A. (1994). "Employers' Expectations of Incoming Graduates: From Recruiters' Views," Journal of Computer Information Systems, 35(3), 57-59.

20. Kemp, J. (1977). Instructional Design: A Plan for Unit and Course Development. $2^{\text {nd }}$ ed. Belmont, CA: Fearon-Pitman Publishers. 
21. Keys, A. (2002-2003). "Using Group Projects in MIS: Strategies for Instruction and Management," Journal of Computer Information Systems, 43(2), 42-50.

22. Knowles, M. (1980). The Modern Practice of Adult Education: From Pedagogy to Andragogy. New York, NY: Cambridge Books.

23. Kruck S. \& Reif, H. (2001). “Assessing Individual Student Performance in Collaborative Projects: A Case Study," Information Technology, Learning, and Performance Journal, 19(2), 7-47.

24. Litecky, C., Arnett, K., \& Prabhakar, B. (2004). "The Paradox of Soft Skills Versus Technical Skills in IT Hiring," Journal of Computer Information Systems, 45(1), 69-76.

25. Longmore, M., Jarboe, G., \& Dunn, D. (1996). “Learning by Doing,” Teaching Sociology, 24, 84-91.

26. McCullough, P. \& Faught, S. (2005). “Rational Moralists and Moral Rationalists Value-

Based Management: Model, Criterion and Validation,” Journal of Business Ethics, 60(2), 195-207.

27. Mennecke, B. \& Bradley, J. (1998). "Making Project Groups Work: The Impact of Structuring Group Roles on the Performance and Perception of Information Systems Project Teams,” Journal of Computer Information Systems, 39(1), 30-36.

28. Naumes, W. and Naumes, M. (1999). The Art \& Craft of Case Writing. Thousand Oaks, CA: Sage Publications.

29. Neilson, R. \& Stouffer, D. (2005). "Narrating the Vision: Vignettes in Action," The Futurist, 2630.

30. Nilson, L. (2003). Teaching at its Best: A Research-Based Resource for College Instructors. $2^{\text {nd }}$. Ed. Bolton, MA: Anker Publishing Co.

31. "Our First Stories." The Call of Story Website. Available at www.callofstory.org/en/storytelling/history.asp, Accessed July 17, 2006.

32. Richards, T., Yellen, R., Kappelman, L. \& Guynes, S. (1998). "Information Managers' Perceptions of IS Job Skills," Journal of Computer Information Systems, 38(3), 53-57.

33. Tang, H-L., Lee, S. \& Koh, S. (2000-2001). "Educational Gaps as Perceived by IS Educators: A Survey of Knowledge and Skill Requirements," Journal of Computer Information Systems, 41(2), 76-84.

34. Trauth, E., Farwell, D. \& Lee, D. (1993). "The IS Expectation Gap: Industry Expectations
Versus Academic Preparation,” MIS Quarterly, 17(3), 293-307.

35. Van Slyke, C., Kittner, M. \& Cheney, P. (1998). "Skill Requirements for Entry-Level IS Graduates: A Report from Industry," Journal of Information Systems Education, 9(3), 6-10.

36. Vik, G. (2001). "Doing More to Teach Teamwork than Telling Students to Sink or Swim," Business Communication Quarterly, 64(4), 112-119.

37. Yamane, D. (1996). "Collaboration and Its Discontents: Steps Toward Overcoming Barriers to Successful Group Projects," Teaching Sociology, 24, 378-383.

38. Young, D. \& Lee, S. (1996). “The Relative Importance of Technical and Interpersonal Skills for New Information Systems Personnel," Journal of Computer Information Systems, 37(4), 66-71. 


\section{Appendix. Sample Team Vignettes}

Vignette 1: A group met at 10 p.m. the night before a project phase was due to assemble their work to turn in the next morning. As they looked at each other's work prior to putting it in the group binder, Maria noticed that Harvey misunderstood the whole purpose of one of the case requirements and saw that his work was "way off the mark" in terms of what was expected. Other team members did not catch this mistake. Maria was unsure what to do. If she raised the issue, she was afraid of criticizing another team member's work. In addition, if that part of the project had to be redone, she knew it would mean staying up to midnight to redo it and she had to work early the next morning. Maria decided to keep quiet and not raise the issue. The team submitted the project to the instructor the next morning.

Vignette 2: David is a highly motivated student who strives to get an A in every class. So far, he has been successful in maintaining a four-point average. David's systems analysis and design teacher just assigned the class the first phase of a group project. When the group met outside of class for the first time to start the project which was due in two weeks, David gave his fellow group members a copy of an entire solution to the case that he developed on his own. His fellow group members looked at David's solution, and one group member, Jeremy, summarized the thoughts of the rest of the group by saying, "Wow David, this is great. I guess our work is done for this phase. Thanks a million!” The group turned in David’s solution to their instructor two weeks later.

Vignette 3: The members of a group in a systems analysis and design class disagreed over what should be done in one important part of a project phase submission. About half of the group felt one way, while the remaining members favored the opposite view. After three or four minutes of disagreeing, the group agreed to vote on the issue. One side won by a 3-2 margin, and the group proceeded with the majority view.

Vignette 4: Marie is a full-time student. To meet rising tuition, she has decided she needs to work full-time Monday through Friday at a local health club. She takes her classes in the late afternoon and evenings. One course is systems analysis and design. Marie's instructor assigned the class to do various project phases, which requires group work to be done outside of class on a regular basis. Due to her work and school schedule, the only time Marie has available to meet with her group is on the weekends. At the start of the term, Marie told her group she could not meet during the week, but she was available to meet anytime on weekends. However, one group member who lives fifteen miles from campus didn't like the idea of having to drive to campus on the weekends for meetings. In addition, all of the other group members didn't like the idea of meeting on weekends when everyone else could meet during the week. The other members decided to hold their group meetings during the week and complete the project on their own.

Vignette 5: A group member in a systems analysis and design class, Jacob, was presented with a remarkable opportunity. His parents offered to take him and his entire family to the Caribbean for two weeks, exactly two weeks before the start of the university's spring break. His parents booked the trip at that time because airline rates were cheaper. Jacob hated Michigan winters, so he couldn't pass up this offer. He told his group members about his plans the day before he left. That was the same day that Jacob's systems analysis and design instructor assigned the class a project phase that was to be completed in two weeks and handed in just before spring break. Jacob's fellow group members completed the phase on their own and submitted it on time. Jacob got equal credit for the phase along with the other members of his group. 
Table 1. Participants' Perceptions of the Team Vignettes

\begin{tabular}{|l|c|c|c|c|c|c|c|c|}
\hline & $\begin{array}{c}\text { Overall } \\
\text { Mean }\end{array}$ & $\begin{array}{c}\text { Overall } \\
\text { SD }\end{array}$ & $\begin{array}{c}\text { Grad } \\
\text { Mean }\end{array}$ & $\begin{array}{c}\text { Grad } \\
\text { SD }\end{array}$ & $\begin{array}{c}\text { UG } \\
\text { Mean }\end{array}$ & $\begin{array}{c}\text { UG } \\
\text { SD }\end{array}$ & t & p \\
\hline $\begin{array}{l}\text { The group vignettes exercise was } \\
\text { useful }\end{array}$ & 5.79 & 1.27 & 6.39 & 0.97 & 5.56 & 1.30 & 3.71 & $.000^{* * *}$ \\
\hline $\begin{array}{l}\text { The group vignettes exercise gave } \\
\text { us practice solving group } \\
\text { problems we might face }\end{array}$ & 6.01 & 0.95 & 6.41 & 0.77 & 5.86 & 0.97 & 3.28 & $.001^{* *}$ \\
\hline $\begin{array}{l}\text { In future semesters, the group } \\
\text { vignettes exercise should be used } \\
\text { in this course }\end{array}$ & 5.86 & 1.19 & 6.44 & 0.92 & 5.64 & 1.21 & 3.83 & $.000^{* * *}$ \\
\hline $\begin{array}{l}\text { By discussing the vignettes in } \\
\text { class, I heard some ideas } \\
\text { expressed by others that I did not } \\
\text { think about previously }\end{array}$ & 5.18 & 1.54 & 5.69 & 1.44 & 5.00 & 1.54 & 2.45 & $.016 *$ \\
\hline $\begin{array}{l}\text { The group vignettes exercise was } \\
\text { worth the time and effort (rc) }\end{array}$ & 5.56 & 1.45 & 6.05 & 1.43 & 5.38 & 1.43 & 2.57 & $.011 * *$ \\
\hline $\begin{array}{l}\text { The group vignettes exercise } \\
\text { raised some possible problems } \\
\text { about working in groups that I } \\
\text { never thought about before }\end{array}$ & 4.51 & 1.76 & 4.78 & 1.92 & 4.41 & 1.70 & 1.14 & .257 \\
\hline $\begin{array}{l}\text { It should not be assumed that we } \\
\text { know how to work in groups so } \\
\text { time should be spent on the group } \\
\text { vignettes exercise (rc) }\end{array}$ & 5.28 & 1.52 & 5.54 & 1.78 & 5.18 & 1.40 & 1.27 & .205 \\
\hline $\begin{array}{l}\text { If some of the problems described } \\
\text { in the group vignettes actually } \\
\text { happened, they could have an } \\
\text { important effect on whether a } \\
\text { group achieved success on a } \\
\text { project }\end{array}$ & 6.26 & 0.90 & 6.41 & 1.02 & 6.20 & 0.85 & 1.29 & .198 \\
\hline
\end{tabular}

$* \mathrm{p}<.05 ; * * \mathrm{p}<.01 ; * * * \mathrm{p}<.001$

These items are based on the seven-point scale: $7=$ strongly agree, $6=$ moderately agree, $5=$ slightly agree, $4=$ neither agree nor disagree, $3=$ =slightly disagree, $2=$ moderately disagree, and 1=strongly disagree.

(rc) Indicates a reverse coded question. These items were asked in a "negative" way in the survey, but they are presented in this table in an opposite (positive) direction to facilitate response comparison across all items 